\title{
Effect of Kidney Malignant Tissues on Antenna Resonance
}

\author{
M. H. Hassan*, A. M. M. A. Allam \\ Faculty of Information Engineering and Technology, German University in Cairo, Cairo, Egypt \\ *Corresponding Author: mohammed_hisham88@hotmail.com
}

Copyright $(02014$ Horizon Research Publishing All rights reserved.

\begin{abstract}
A logarithmic spiral microstrip antenna (LSMA) is designed, simulated and measured in rabbit's kidney. The antenna operates in the Medical Implant Communications Service (MICS) band at $403 \mathrm{MHz}$. It is fabricated on Rogers RT6010 (lossy) with relative dielectric constant of 10.2 and thickness $1.9 \mathrm{~mm}$. There is a good agreement between the measured and simulated results for LSMA in rabbit's kidney. A study is made to observe the effect of malignant tissues on the performance of the antenna. Results are considered as brain stone for early detection diagnosis for cancer.
\end{abstract}

Keywords Implanted Antenna, Spiral Microstrip Antenna, Logarithmic Spiral Microstrip Antenna (LSMA), Medical Implant Communications Service (MICS), Malignant Tissues, Wireless Technology

\section{Introduction}

Wireless technology is one of the fastest growing industries throughout the world. In implanted systems, the implanted systems is connected either to the patient's cell phone or computer system, which sends and receives medical reports using the wireless technology. This system is similar to a home care unit which eases the patients by cutting off the long, regular hospital visits [1]-[6].

Implanted antennas are used as biomedical applications to cure or detect certain diseases inside the body. It can be implanted inside the body or embedded under the skin. This depends whether it elevates the temperature of the patient's body or not. Different shapes and types of antennas can be used depending on where it would be implanted inside the body. These types include; dipole, loop, microstrip and PIFA antennas [7].

Cancer is becoming one of the most common diseases in the world, which invades the body. For this reason, cancer detection is becoming one of the most serious topics in the medical industry. The main problem for cancer detection is that a sample should be taken from the patient and in this case it is considered destructive. In this paper, a brain stone for detecting cancer in the human body is presented.
This paper presents an LSMA for early detection diagnosis for cancer. It studies the effect of tumor cells on the antenna performance [8].

\section{Antenna Design}

An LSMA embedded in a substrate is shown in Fig.1. The antenna width starts with width; $W$ which keeps decreasing by a factor of 1.44 until it reaches to a minimum width of 0.2 $\mathrm{mm}$. The antenna has the phenomena of both the spiral behavior and the log periodic behavior. It should be pointed out that this width is manufactured constraint. It occupies an area of $L_{4} \times L_{5}$. The antenna is made of lossy copper and of thickness; $t_{2}$. The antenna is covered with superstrate of equal length of that of the substrate; $L_{2}$, width; $L_{l}$ and height; $t_{1}$. The substrate and superstrate are made of Rogers RT6010 and of thickness; $\mathrm{t} 1$. A coaxial probe and shorting pin of radius; $r_{1}$ are located as shown in Fig. 1 (b).Table I, lists the design dimensions for LSMA.
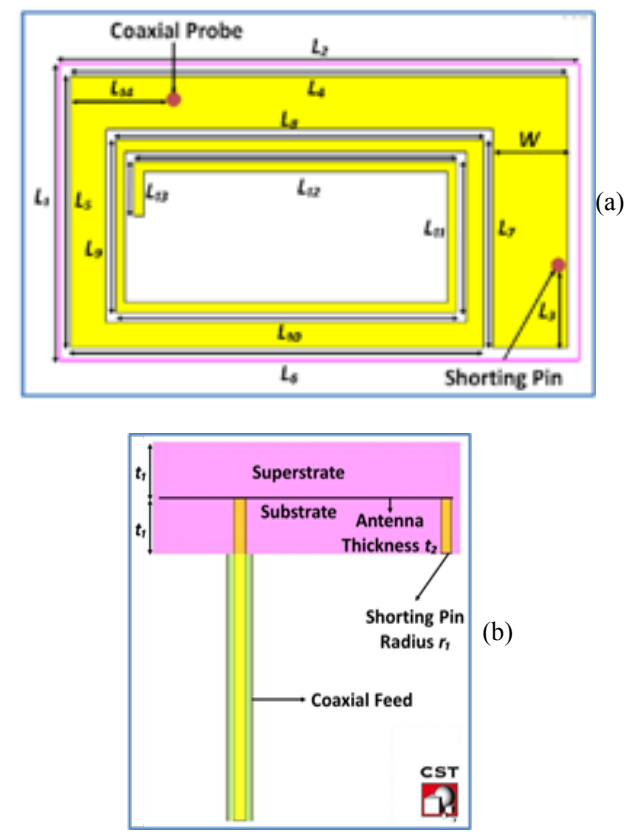

Figure 1. Geometry of embedded LSMA (a) top view (b) side view 
Table I. Design Dimensions of LSMA

\begin{tabular}{cccc}
\hline Parameters & LSMA(mm) & Parameters & LSMA(mm) \\
\hline $\mathrm{L}_{1}$ & 6 & $\mathrm{~L}_{10}$ & 7.22 \\
$\mathrm{~L}_{2}$ & 11 & $\mathrm{~L}_{11}$ & 3.05 \\
$\mathrm{~L}_{3}$ & 0.85 & $\mathrm{~L}_{12}$ & 6.82 \\
$\mathrm{~L}_{4}$ & 10.5 & $\mathrm{~L}_{13}$ & 1.1 \\
$\mathrm{~L}_{5}$ & 5.5 & $\mathrm{~L}_{14}$ & 2.39 \\
$\mathrm{~L}_{6}$ & 8.72 & $\mathrm{~W}_{1}$ & 1.57 \\
$\mathrm{~L}_{7}$ & 4.21 & $\mathrm{t}_{1}$ & 1.9 \\
$\mathrm{~L}_{8}$ & 7.78 & $\mathrm{t}_{2}$ & 0.015 \\
$\mathrm{~L}_{9}$ & 3.49 & $\mathrm{r}_{1}$ & 0.25 \\
\hline
\end{tabular}

The antenna structure is placed in a kidney phantom block of permittivity of 66.4 and electrical conductivity of 1.1 as shown in Fig.2.

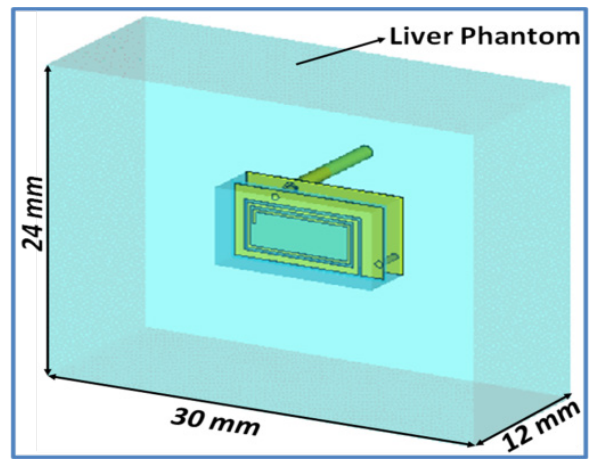

Figure 2. Placement of LSMA in liver phantom block

\section{Simulation and Results}

The antenna is designed using computer simulation technology microwave studio (CST MWS). Fig.3, illustrates the return loss of LSMA. The antenna resonates at $403 \mathrm{MHz}$ with bandwidth of $18.11 \mathrm{MHz}$.

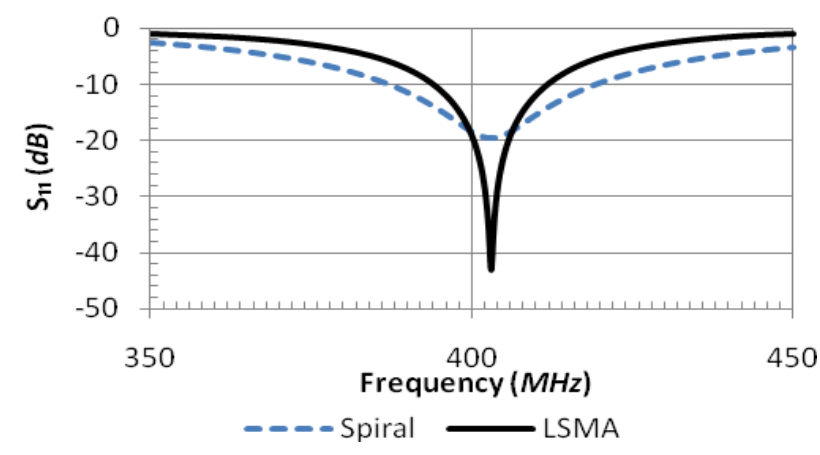

Figure 3. Simulated return loss in spiral and LSMA

\section{Antenna Fabrication}

The designed antenna is fabricated using Rogers material
Duroid $6010\left(\varepsilon_{\mathrm{r}}=10.2, \delta=0.0023\right.$, thickness $\left.=1.9 \mathrm{~mm}\right)$ as shown in Fig.4 (a), (b), (c).

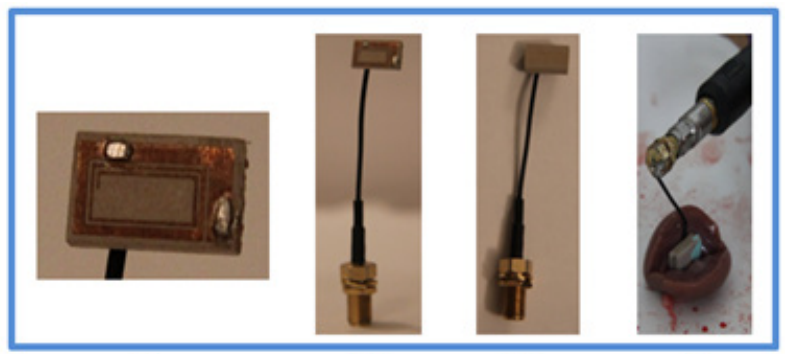

(a)

(b)

(c)

(d)

Figure 4. Fabricated LSMA (a) etched in substrate, (b) without superstrate, (b) with superstrate, (c) in kidney

A rabbit's kidney is used to resemble the human kidney while the antenna is immersedas shown in Fig.4(d). Fig. 5 depicts both the measured and simulated return loss.

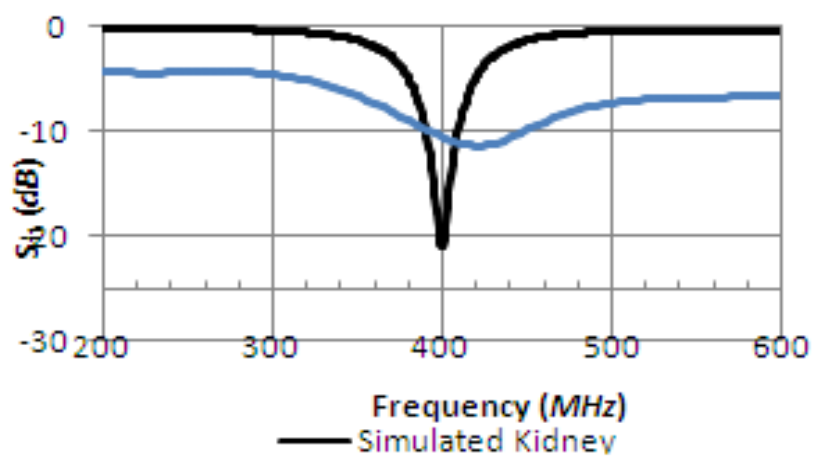

Figure 5. Return loss of measured vs. simulated LSMA inside the kidney

It is clear that the measured results show an acceptable match to the simulated results. The measured curve is slightly shifted from the simulated one due to the properties of the rabbit's kidney is slightly different from those the human, the antenna is immersed after the kidney is totally removed from the rabbit hence there is a partial absence of blood and salts, blu-tac attaching the substrate with the superstrate affects the sensitivity of the antenna, and the antenna gets affected to any liquid exposure [8].

\section{Effect of Malignant Tissues on Antenna Resonance}

A study is made to observe the effect of malignant tissues on the performance of the antenna. According to Joines, W. T. et al.[9]; both the relative permittivity and conductivity of these tissues are greater than in normal tissues. The differences in electrical properties of kidney tissues from normal to malignant are about $6 \%$. Hence the permittivity and conductivity of the kidney are 70.34 and 1.16 relative to 66.4 and 1.1 respectively. The study comprises 6 steps.

1. One malignant tissue is designed to cover one side of the antenna and of volume $196 \mathrm{~mm} 3$. It occupies $2.27 \%$ of the phantom and is located as shown in Fig. 6. 


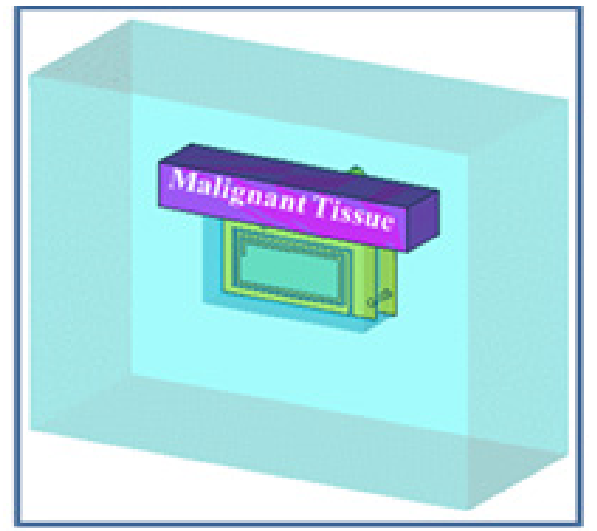

Figure 6. Presence of malignant tissue (volume $196 \mathrm{~mm} 3$ )

2. The malignant tissue is designed to cover two sides of the antenna having a volume of $265 \mathrm{~mm} 3$. It occupies $3 \%$ of the phantom and is located as shown inFig.7.

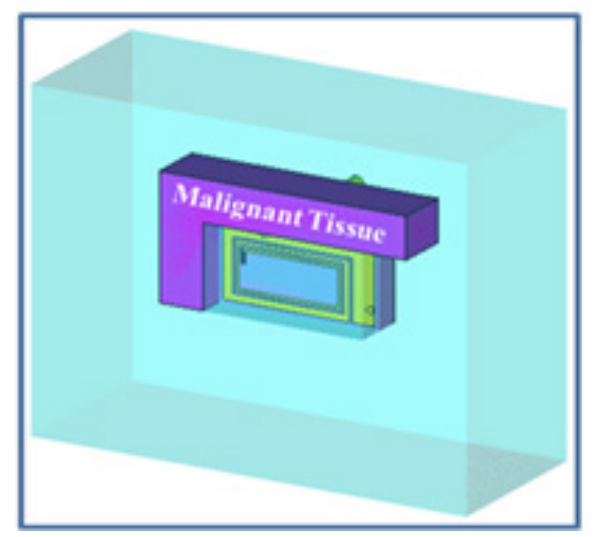

Figure 7. Presence of malignant tissue (volume $265 \mathrm{~mm} 3$ )

3. The malignant tissue is designed to cover the four sides of the antenna having a volume of $530 \mathrm{~mm} 3$. It covers $6.14 \%$ of the phantom and is situated as demonstrated inFig.8.

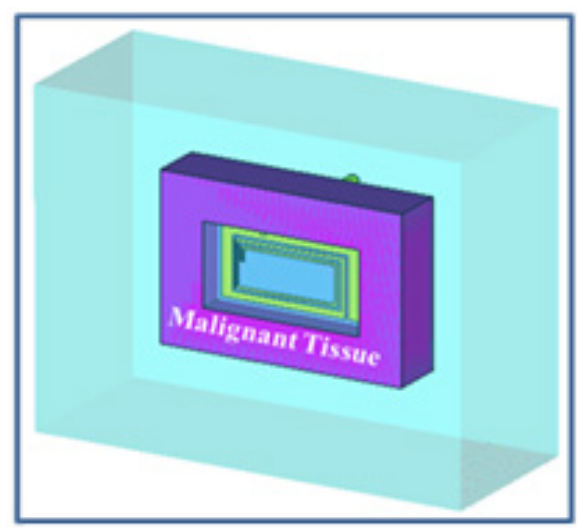

Figure 8. Presence of malignant tissue (volume $530 \mathrm{~mm} 3$ )

4. The malignant tissue is designed to cover the antenna throughout the whole surface of the phantom. It has a volume of $2422 \mathrm{~mm} 3$ and fills $28 \%$ of the phantom as shown in Fig.9.

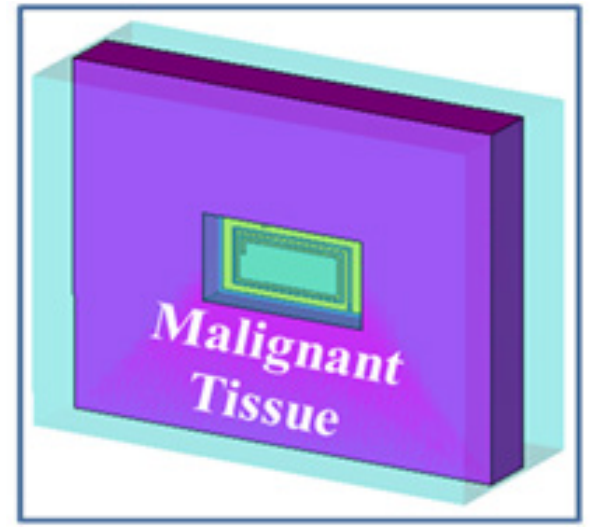

Figure 9. Presence of malignant tissue (volume $2422 \mathrm{~mm} 3$ )

5. The malignant tissue throughout the surface of the phantom aligned with the antenna gets covered to fill the top surface of the antenna. It has a volume of 5258 $\mathrm{mm} 3$ and covers $60.9 \%$ of the phantom as depicted in Fig.10.

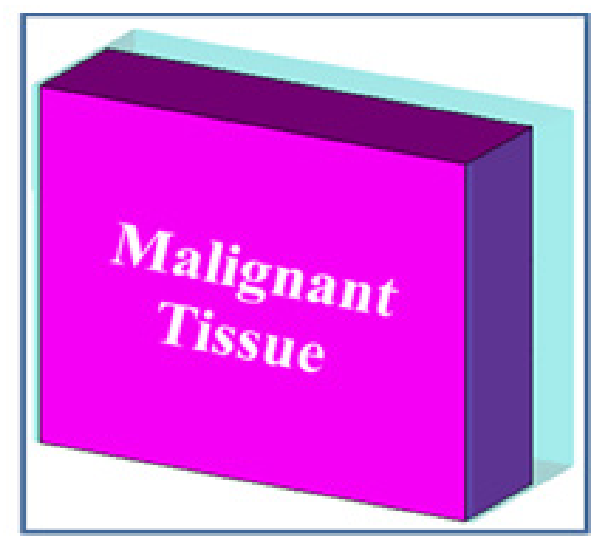

Figure 10. Presence of malignant tissue (volume $5258 \mathrm{~mm} 3$ )

6. Finally, the malignant tissue is designed to cover the antenna entirely from top, bottom and surface having a volume of $8076 \mathrm{~mm} 3$. It covers $93.5 \%$ of the phantom as represented in Fig.11.

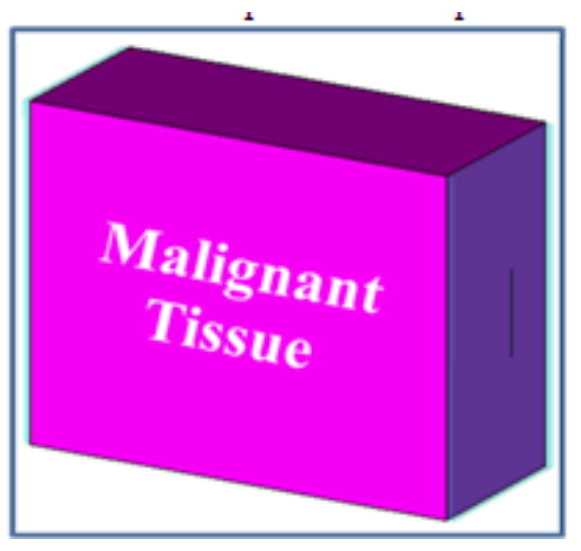

Figure 11. Presence of malignant tissue (volume $8076 \mathrm{~mm}^{3}$ )

Fig.12 illustrates the antenna response to each volume of malignant tissue mentioned previously. It is clear that as the 
volume of malignant tissues increase; the antenna resonates at a smaller frequency outside the MICS band.

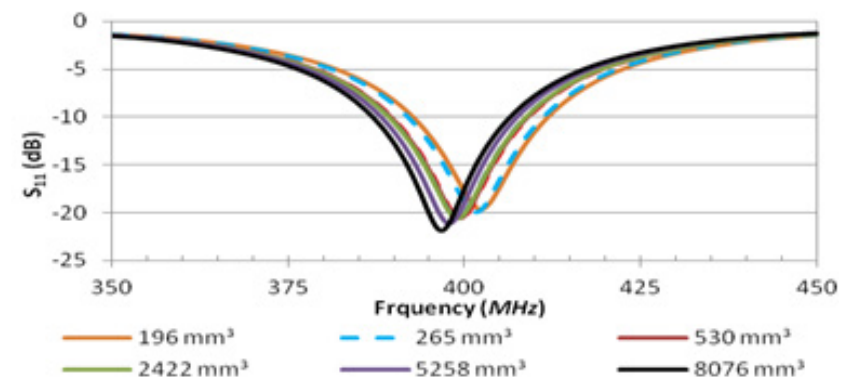

Figure 12. Simulated return loss for different volume of malignant tissues

Table II depicts each volume and its correspondent resonant frequency shift from $403 \mathrm{MHz}$. Fig. 13 demonstrates the relation between the volume of malignant tissues and the resonant frequency.

TABLE II. Different volume of malignant tissues and its correspondent resonant frequency

\begin{tabular}{ccc}
\hline Volume $\left(\mathrm{mm}^{3}\right)$ & Frequency $(\mathrm{MHz})$ & Return loss $(\mathrm{dB})$ \\
\hline 196 & 402.3 & -19.65 \\
265 & 401.6 & -20 \\
530 & 399.3 & -20.59 \\
2422 & 399 & -20.55 \\
5258 & 397.8 & -21.11 \\
8076 & 396.7 & -21.84 \\
\hline
\end{tabular}

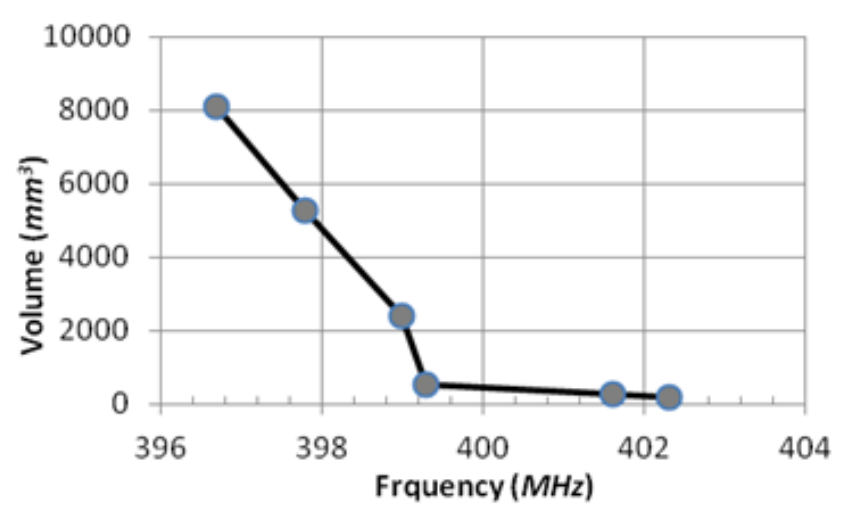

Figure 13. Volume of malignant tissues vs. resonance frequency

One concludes that increasing the dimensions of malignant tissues in the kidney results in; negative shift of the resonant frequency withnon significant change in the bandwidth. These results are considered as brain stone for early detection diagnosis of cancer. The tumor tissues of volume percentage of $2.27,3,6.14,28,60.9$ and 93.5 conduct a shift of $0.7,1.4,3.7,4,5.2$ and $6.3 \mathrm{MHz}$ respectively.
A logarithmic spiral microstrip antenna (LSMA) is designed, simulated and measured in a rabbit's kidney. The antenna achieves resonance at $403 \mathrm{MHz}$. Fabricated and simulated LSMA show a good agreement. The study which is made on the presence of malignant tissues shows that the antenna can be used as a tool for early detection diagnosis for cancer. Moreover; it can indicate in which cancerous stage is the tumor; depending on the frequency shift.

\section{REFERENCES}

[1] P. S. Hall and Y. Hao, "Antennas and Propagation for Body-Centric Wireless Communications," Norwood, MA: Artech House, ch. 9., 2006.

[2] R. Warty, M. R. Tofighi, U. Kawoos, and A. Rosen, "Characterization of implantable antennas for intracranial pressure monitoring: Reflection by and transmission through a scalp phantom," IEEE Trans. Microwave Theory Tech., vol. 56, pp. 2366-2376, Oct. 2008.

[3] T. Dissanayake, K. P. Esselle, and M. R. Yuce, "Dielectric loaded impedance matching for wideband implanted antennas," IEEE Trans. Microwave Theory Tech., vol. 57, pp. 2480-2487, Oct. 2009.

[4] S. Soora, K. Gosalia, M. S. Humayun, and G. Lazzi, “A comparison of two and three dimensional dipole antennas for an implantable retinal prosthesis," IEEE Trans. Antennas Propag., vol. 56, pp. 622-629, Mar. 2008.

[5] T. Karacolak, R. Cooper, and E. Topsakal, "Electrical properties of rat skin and design of implantable antennas for medical wireless telemetry," IEEE Trans. Antennas Propag., vol. 57, pp. 2806-2812, Sep. 2009.

[6] C. H. Durney and M. F. Iskander, "Antennas for medical applications," in Antenna Handbook, Y. T. Lo and S.W. Lee, Eds. New York: Van Nostrand, ch. 24., 1988.

[7] Jaehoon Kim; Rahmat-Samii, Y.; , "SAR reduction of implanted planar inverted $\mathrm{F}$ antennas with non-uniform width radiator," Antennas and Propagation Society International Symposium 2006, IEEE, vol., no., pp.1091-1094, 9-14 July 2006.

[8] M. H. Hassan; A. M. M. A. Allam; , “A Novel Implanted Logarithmic Spiral Antenna, " accepted in IEEE conference APCAP in Thailand, 5-8 August 2013.

[9] Joines, W. T.; Zhang, Y.; Li, C.; Jirtle, R. L.; "The measured electrical properties of normal and malignant human tissues from 50 to $900 \mathrm{MHz}$ " Med. Phys. 21 547-50 1994.

\section{Conclusion}

